Journal of Applied Fluid Mechanics, Vol. 14, No. 6, pp. 1669-1678, 2021. Available online at www.jafmonline.net, ISSN 1735-3572, EISSN 1735-3645. https://doi.org/10.47176/jafm.14.06.32435

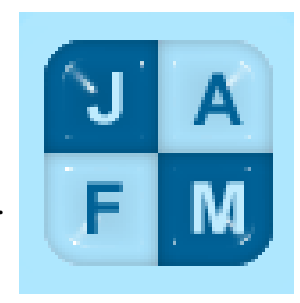

\title{
Vortex Evolution and Energy Production in the Blade Channel of a Francis Turbine Operating at Deep Part Load Conditions
}

\author{
A. Yù, Y. S. Wang and D. Q. Zhou \\ College of Energy and Electrical Engineering, Hohai University, Nanjing, China \\ †Corresponding Author Email: yu_an@hhu.edu.cn
}

(Received December 3, 2020; accepted May 2, 2021)

\begin{abstract}
The blade vortex evaluation in Francis Turbine under deep part load conditions generates severe pressure fluctuations in the runner. The complex flow in a model turbine is numerically investigated based on a modified Partially Averaged Navier-Stokes method. The main emphasis is focused on revealing the correlation mechanism of blade vortex evolution and energy production. The results indicate that the modified PANS method shows significant advantages in hydro turbine's simulation than the traditional RANS method. At deep part load conditions, the vorticity formed at the leading edge of the suction surface and the trailing edge of the pressure surface in the blade channels. The stretching term provides the most vorticity increments while the dilation term inhibiting part which only provides a decrement of the vorticity evolution. Based on the entropy production theory, the total entropy production distribution is consisting with the distribution of vorticity. At deep part load condition, direct dissipation and turbulent dissipation provide the most entropy, while at part load condition the proportion of these twopart decreased.
\end{abstract}

Keywords: Francis turbine; Vortex evolution; Energy Production; Vorticity transport equation; Entropy production theory.

\section{NOMENCLATURE}

$\begin{array}{ll}\text { LES } & \text { Large Eddy Simulation } \\ \text { DES } & \text { Detached Eddy Simulation } \\ \text { RANS } & \text { Reynolds-Averaged Navier-Stokes } \\ \text { PANS } & \text { Partially Averaged Navier-Stokes } \\ \text { EPTD } & \text { Indirect or Turbulent Dissipation } \\ \text { EPDD } & \text { Direct Dissipation } \\ \text { EPWS } & \text { Wall Entropy Production } \\ \text { CFD } & \text { Computational Fluid Dynamics } \\ p & \text { pressure } \\ q & \text { heat flux } \\ s & \text { entropy per unit mass } \\ T & \text { local temperature } \\ \bar{u} \bar{v} \bar{w} & \text { time-averaged velocity } \\ u v w & \text { Velocity components } \\ \mu & \text { viscosity }\end{array}$

$\begin{array}{ll}\mu_{m} & \text { mixture molecular viscosity } \\ \mu_{t} & \text { mixture molecular viscosity } \\ \rho & \text { density } \\ a_{0} & \text { guide vane opening } \\ v & \text { kinematic viscosity } \\ v_{\mathrm{tur}} & \text { turbulent kinematic viscosity } \\ v_{\mathrm{W}} & \text { first grid velocity near the wall } \\ \tau & \text { wall shear stress } \\ \omega & \text { vorticity } \\ \kappa & \text { turbulent kinetic energy } \\ \Phi & \text { dissipation function } \\ C_{\varepsilon 1} & 1.44 \\ \sigma_{\mathrm{k}} & 1.0 \\ \sigma_{\varepsilon} & 1.3\end{array}$

\section{INTRODUCTION}

As society pays more attention to environmental protection, the proportion of clean energy such as wind energy and solar energy in the power system is

higher and higher. The hydro turbine which is the pivotal part for conversion of energy forms in hydropower stations often operates at deep part load conditions to ensure the stability of the power system and compensate for the stochastic nature of variable energy sources. 
When the turbine is operating at deep part load conditions, its operation stability and other related problems gradually become prominent, especially the emergence of blade vortex, which threatens the operation of power station units stably and safely.

Kurosawa et al. (2010) and Kumar and Saini (2010) observed A continuous vortex tube between adjacent runner blades at partial discharge, during the physical reduced scale model tests of a Francis turbine. This special vortex structure is called the inter-blade vortex that attaches to the runner hub and extends up to the trailing edge of the runner blade. (Luo et al. 2016) If the blade vortex is unstable, there is a risk of blade depth corrosion and cause pressure pulsations (Escaler et al. 2006). In addition, the amplitude of the static stress will suddenly increase with the formation of blade vortex (Chen et al. 2007). All of the above will affect the safe and stable operation of the unit.

Thus, the influence of blade vortex on the safe and stable operation of the unit cannot be ignored. The mechanisms and patterns of blade vortex are worthy of our in-depth studies, which is of great significance for eliminating or eradicating the damage of hydraulic vibration and noise caused by blade vortex and improving the safe and effective utilization of hydraulic resources.

At present, experts and scholars have made in-depth research on blade vortex from two aspects: experimental research and numerical simulation, and have achieved fruitful results.

In 2017, Liu et al. (2017) observed the blade vortex evolution from inception to collapse through a highspeed camera, and studied the effects of different hydraulic parameters, revealing that under deep part load conditions, the blade vortex is mainly caused by the large incident angle between influx angle and leading edge blade angle of flow passage. Yamamoto et al. $(2015,2016,2017)$ have carried out experiments and numerical research on blade vortex of hydraulic turbine and put forward an embedded visualization technique of movable guide vane, which can be used to more intuitively observe the blade vortex flow structure from the wheel inlet. Roth et al. (2010) of the Lausanne Institute of Technology in Switzerland measured the hydrodynamic pressure and dynamic stress of the runner using a dynamic pressure transducer and strain gauge embedded in the blade of the runner. The results show that the hydrodynamic pressure and the dynamic stress on the runner are closely related to the operating conditions. The amplitude of pressure pulsations and dynamic stress caused by the blade vortex are obviously stronger than those under other operating conditions.

Up to now, most of the studies on the blade vortex are completed by means of CFD (Computational Fluid Dynamics). There are three kinds of available numerical methods: RANS(Reynolds-Averaged Navier-Stokes) LES (Large Eddy Simulation) and DNS(Direct Numerical Simulation). However, DNS consumes a lot of computing resources and has high requirements for grids, which makes it difficult to be applied to the numerical simulation of turbine. Therefore, the RANS and LES methods have become the main methods for most scholars to study the internal flow field of the hydraulic turbine.

Wang et al. (2007) carried out LES simulation of a single-flow model with a single-flow turbine. He found that the strong wake would cause the largearea flow separation at the leading edge of the blade and form the main vortex along the spreading direction. Kurosawa et al. (2010) used the Reynolds Stress Model and the gas-liquid multiphase model to solve the unstable Reynolds Averaged NavierStokes equation and to simulate the shape of the blade vortex. Wack and Riedelbauch (2015) found that the simulation of the blade vortex is quite sensitive to the local mesh size. Kumar and Saini (2010) found that the emergence of blade vortex is very sensitive to the guide vane opening. When the guide vane opening and flow rate decreases, the intensity of inter-blade-vortex will significantly increase. What's more, Amet et al. (2009) carried out a two-dimensional numerical simulation of blade vortex interaction and qualitatively compared the results with the visualization of the vortex shedding. Xiao et al. (2011) used the SST $k-\varepsilon$ turbulence model to analyze the instability of the runner blade vortex. The results show that the frequency of blade vortex is relatively low and it changes with the change of operating conditions. Similarly, Zuo et al. (2015) carried out a two-phase numerical simulation of a mixed flow model turbine and obtained two different types of inter-blade-vortex: stable columnar interblade-vortex and unstable streamline blade vortex. In addition, he pointed out that the frequency of the blade vortex is about 0.84 times that of the rotation frequency, and the frequency of blade vortex development conditions is about 1.0 times rotation frequency.

Most recently, Cheng et al. (2020) used the Very Large Eddy Simulation method to study the blade vortex in a Francis turbine, the flow pattern revealed that the direct relationship of a backflow region and the blade attacking angle near the hub had a distinct variation in vortex structure and intensity. Doussot $e t$ al. (2019) used RANS and LES methods to study the simplified low-head turbine runner model and found that RANS and LES methods can accurately predict the position and 3D topological structure of the interblade-vortex. According to their topology structure and driving phenomena, vortices are divided into four categories, and each one corresponds to a dynamic characteristic determined by its operating conditions. Through numerical simulation research, Yamamoto et al. (2019) revealed the physical mechanism of vortex development between Francis turbine blades under deep part load. In recent years, there are many new advances in the research of vortex instability at the blade of turbine. Méndez et al. (2018) found vortical structures which have the form of steady streamwise-oriented counter-rotating vortex pairs known as Gortler instability on the pressure side of the turbine blade. Also, through the numerical simulation of a propeller, Jing and Ducoin (2020) found that in the suction side of the blade the flow is susceptible to the crossflow instabilities. 
Moreover, the energy characteristics of hydro turbine are getting more and more attention Recently, a new method is developed to evaluate flow energy loss based on the second thermodynamic law which is entropy production theory. Kock et al. (2004, 2005) and Herwig et al. (2006) used time-averaged method on entropy production equation and obtained four entropy production terms which can be calculated directly in CFD post. Duan et al. (2016) proposed a simple wall entropy production method to made up the inaccuracy of Kock's method in calculation of wall region. $\mathrm{Li}$ et al. $(2016,2017)$ introduced the entropy production theory to determine the flow losses in the whole passage of turbine, based on the numerical simulation. The variation of entropy production under different guide vane openings is presented by him. Besides, a wall equation was proposed to calculate the hydraulic loss in the wall region. It also proves the feasibility and accuracy of using RANS method to calculate the entropy production.

In summary, the inter-blade vortex evolution is one of the critical issues when turbines operating under deep part load conditions. But there are not so many further researches on unsteady behaviors and energy performances of inter-blade vortices. Moreover, the conventional RANS method is not able to predict many vortical behaviors for flow over a blade. Thus, numerical simulation of complex vortex flow was carried out based on a modified PANS method in a model turbine. The correlation mechanism between inter-blade vortex evolution and energy performances is deeply discussed based on the vorticity transport equation and entropy production theory.

\section{SiMULATION METHODS}

The internal flows in the turbine operating under deep part load conditions usually concomitant with the swirling flow.

The basic governing equations are:

$$
\begin{aligned}
& \frac{\partial \rho}{\partial t}+\frac{\partial\left(\rho u_{j}\right)}{\partial x_{j}}=0 \\
& \frac{\partial \rho u_{\mathrm{i}}}{\partial t}+\frac{\partial \rho u_{\mathrm{i}} u_{\mathrm{j}}}{\partial x_{\mathrm{j}}}= \\
& -\frac{\partial p}{\partial x_{\mathrm{i}}}+\frac{\partial}{\partial x_{\mathrm{j}}}\left[\left(\mu_{\mathrm{t}}+\mu_{\mathrm{m}}\right)\left(\frac{\partial u_{\mathrm{i}}}{\partial x_{\mathrm{j}}}+\frac{\partial u_{\mathrm{j}}}{\partial x_{\mathrm{j}}}\right)\right]
\end{aligned}
$$

where $\rho, u$ and $p$ represent the fluid density, timeaveraged velocity and pressure. $\mu_{\mathrm{t}}, \mu_{\mathrm{m}}$ are the turbulent and molecular viscosity.

The traditional URANS turbulence model is widely used in engineering predications, but in detailed investigations, the URANS model cannot reflect the unsteady characteristics of vortical flows. Thus, many modifications of the turbulence model have been presented. The partially Averaged NavierStokes (PANS) method is a classical hybrid method, which combined the URANS and Direct numerical simulation (DNS). This method uses the unresolvedto-total ratios of kinetic energy $\left(f_{\mathrm{k}}\right)$ and dissipation $\left(f_{\varepsilon}\right)$ to quantify the resolution level. In traditional PANS method, $f_{\mathrm{k}}$ is a constant value. Thus, a modified PANS method (Huang et al. 2017) has been proposed and adopted in the present study. The $f_{\mathrm{k}}$ in the modified PANS is a self-adapting value and has been proved its feasibility and reliability in cavitating flow simulation.

The equations of the traditional PANS model are showing in Eqs. (3) (7):

$$
\begin{aligned}
& \frac{\partial k_{\mathrm{u}}}{\partial t}+\frac{\partial\left(u_{\mathrm{i}} k_{\mathrm{u}}\right)}{\partial x_{\mathrm{i}}}= \\
& \frac{\partial}{\partial x_{\mathrm{j}}}\left[\left(v+\frac{v_{\mathrm{u}}}{\sigma k_{\mathrm{u}}}\right) \frac{\partial k_{\mathrm{u}}}{\partial x_{\mathrm{j}}}\right]+P_{\mathrm{u}}-\varepsilon_{\mathrm{u}} \\
& \frac{\partial \varepsilon_{\mathrm{u}}}{\partial t}+\frac{\partial\left(u_{\mathrm{i}} \varepsilon_{\mathrm{u}}\right)}{\partial x_{\mathrm{i}}}= \\
& \frac{\partial}{\partial x_{\mathrm{j}}}\left[\left(v+\frac{v_{\mathrm{u}}}{\sigma k_{\mathrm{u}}}\right) \frac{\partial \varepsilon_{\mathrm{u}}}{\partial x_{\mathrm{j}}}\right]+C_{\varepsilon 1} P_{\mathrm{u}} \frac{\varepsilon_{\mathrm{u}}}{k_{\mathrm{u}}}-C_{\varepsilon 2} \frac{\varepsilon_{\mathrm{u}}^{2}}{k_{\mathrm{u}}} \\
& \sigma_{\mathrm{ku}}=\sigma_{\mathrm{k}} \frac{f_{k}^{2}}{f_{\varepsilon}} \\
& \sigma_{\varepsilon \mathrm{u}}=\sigma_{\varepsilon} \frac{f_{k}^{2}}{f_{\varepsilon}} \\
& C_{\varepsilon 2}=C_{\varepsilon 1}+\frac{f_{k}}{f_{\varepsilon}}\left(1.92-C_{\varepsilon 1}\right)
\end{aligned}
$$

The $f_{\mathrm{k}}$ in the modified PANS model is defined as:

$$
f_{k}=\min \left(1,(\Delta / l)^{2 / 3}\right)
$$

where $\Delta=\left(\Delta \mathrm{x}^{*} \Delta \mathrm{y}^{*} \Delta \mathrm{z}\right) 1 / 3$ is the local mesh size.

\section{MODEL TURBINE STRUCTURE}

The structure of the model turbine used in the study is showing in Fig. 1. Geometry parameters and operating parameters showing in Table 1 are used in the present investigation. Typical deep part load discharge and part load discharge operating conditions with guide vanes opening of $a_{0}=7.92 \mathrm{~mm}$ and $10.2 \mathrm{~mm}$ were chosen.

In this article, the modified PANS method was used and adopted into ANSYS CFX 18.0.

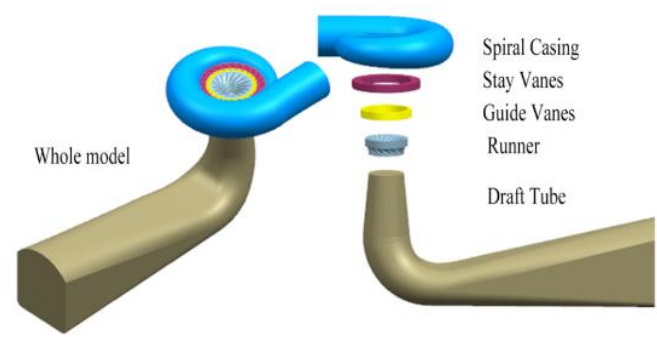

Fig. 1. Computational domain of the model turbine. 
Table 1 Geometric parameters of the model turbine.

\begin{tabular}{|l|r|}
\hline Parameter & Value \\
\hline Mechanical Parameter & 420 \\
\hline Runner inlet diameter $D_{1}[\mathrm{~mm}]$ & 17 \\
\hline Runner blade number $Z_{\mathrm{b}}$ & 23 \\
\hline Stay vane number & 24 \\
\hline Guide vane number & 182 \\
\hline Guide vane height $b_{0}[\mathrm{~mm}]$ & \\
\hline Operating Parameter & $3.9,10.2$ \\
\hline Guide vane opening $a_{0}[\mathrm{~mm}]$ & 30 \\
\hline Head $H[\mathrm{~m}]$ &
\end{tabular}

The time step was set as $0.0001837 \mathrm{~s}$ ( 1 degree per time step). The slipping mesh was applied for the interface between stationary and rotating parts. The frame change/mixing model of the interface model in the steady calculation is frozen rotor, while the model used in the unsteady calculation is transient rotor stator. The advection scheme adopted the mixed solution mode and the transient scheme adopted the second order backward Euler, which had the advantage of good convergence.

\section{ReSUltS}

\subsection{Grid independence and simulation method validation}

Both of stationary and rotary components mesh were hexa-structured and generated by ANSYS ICEM as shown in Fig. 2. Refined mesh was implemented around blades to capture flow separation accurately at leading and trailing edge of blades. However, due to the computational limit, only five different grids were used for grid independence verification. Figure 3 indicated that case 4 with $4.59 \times 106$ nodes is selected as the final scheme in the following simulations after a balance of computational sources and accuracy.

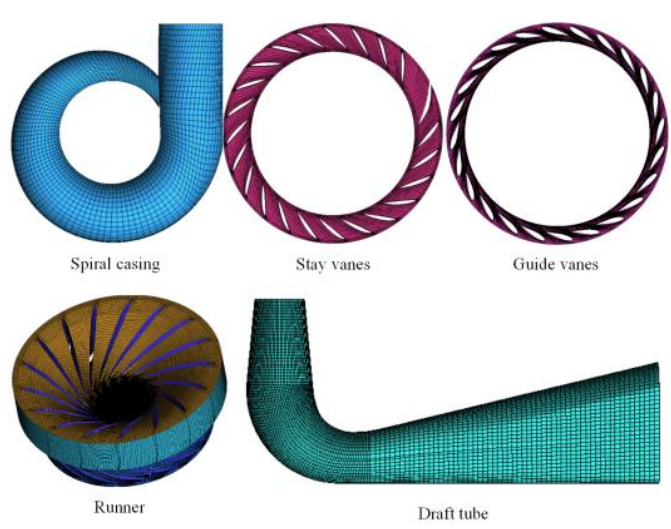

Fig. 2. Grid production of computational domain

The modified PANS method was used in this simulation, and the comparison between simulation and experiment on the model turbine's external performances are presented in Table 2. As presented in Table 2, the differences are acceptable.

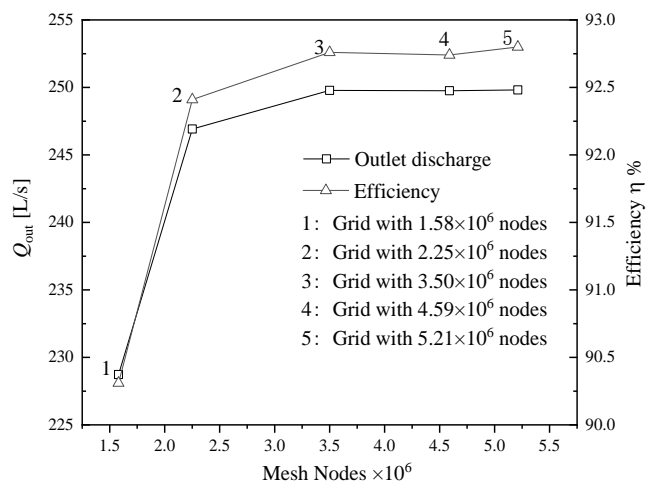

Fig. 3. Outlet discharge and efficiency variation versus different mesh cases.

Table 2 Performance comparison and errors.

\begin{tabular}{|c|c|c|c|}
\hline Parameter & $a_{0}$ & $\begin{array}{c}\text { Flowrate } \\
{[1 / \mathrm{s}]}\end{array}$ & $\begin{array}{c}\text { Efficiency } \\
\eta \%\end{array}$ \\
\hline \multirow{2}{*}{$\begin{array}{c}\text { Numerical } \\
\text { value }\end{array}$} & 7.9 & 169.37 & 80.1 \\
\cline { 2 - 4 } & 10.2 & 203.21 & 86.9 \\
\hline \multirow{2}{*}{$\begin{array}{c}\text { Experimental } \\
\text { value }\end{array}$} & 7.9 & 161.25 & 79.5 \\
\cline { 2 - 4 } & 10.2 & 195.06 & 85.7 \\
\hline \multirow{2}{*}{ Error } & 7.9 & $5.0 \%$ & $0.7 \%$ \\
\cline { 2 - 4 } & 10.2 & $4.2 \%$ & $1.4 \%$ \\
\hline
\end{tabular}

\subsection{Pressure fluctuations at deep part load conditions}

Vortical flow features a complicated and unsteady flow phenomenon. When turbines operated apart from designed conditions, vertical flows formed in different areas of flow passages at different conditions. Large scale vortical flow occurred in the draft tube when operating at about $40 \%$ to $80 \%$ design flow rate.

Table 3 Pressure fluctuations of different monitoring points at different conditions.

\begin{tabular}{|c|c|c|c|}
\hline$a_{0}$ & $\begin{array}{c}\text { Monitoring } \\
\text { point }\end{array}$ & $\begin{array}{c}\text { Dominant } \\
\text { frequency } \\
\left(f / f_{\mathrm{n}}\right)\end{array}$ & $\begin{array}{c}\text { Amplitude } \\
\left(\Delta H / H_{\mathrm{m}}\right)\end{array}$ \\
\hline \multirow{2}{*}{12.2} & $\mathrm{HD}$ & 0.21 & 0.73 \\
\cline { 2 - 4 } & $\mathrm{HSV}$ & 0.21 & 0.51 \\
\hline \multirow{2}{*}{10.2} & $\mathrm{HD}$ & $0.48,0.72$ & $0.17,0.18$ \\
\cline { 2 - 4 } & $\mathrm{HSV}$ & 1 & 0.41 \\
\hline \multirow{2}{*}{7.9} & $\mathrm{HD}$ & $0.79,1$ & $0.21,0.23$ \\
\cline { 2 - 4 } & $\mathrm{HSV}$ & 1 & 0.44 \\
\hline
\end{tabular}

Table 3 gives the dominant pressure fluctuations of two classical points at different operating conditions. Note that $a_{0}=12.2$ equals $65 \%$ designed flow rate while $a_{0}=10.2$ and 7.9 are equal $40 \%$ and $30 \%$ of the designed flow rate. Monitoring point HD is located on the draft tube wall near the runner outlet, while monitoring point $\mathrm{HSV}$ is located on the runner crown. The previous studies show that a helical 
vortex rope formed during this part load condition $\left(a_{0}=12.2\right)$ and generated severe pressure fluctuation $\left(0.21 f_{\mathrm{n}}\right)$ which spread and became the dominant fluctuation in the whole flow passage (HD, HSV). While at deep part load conditions $\left(a_{0}=10.2\right.$ and 7.9), dominant pressure fluctuation is not found in the draft tube (HD). Several pressure fluctuations with small amplitude occurred and didn't spread to the runner. But there is still a dominant pressure fluctuation (amplitude is 0.41 and 0.44 ) with a frequency of $1 f_{\mathrm{n}}$, which is assumed as the inter-blade vortex frequency at the deep part load conditions.
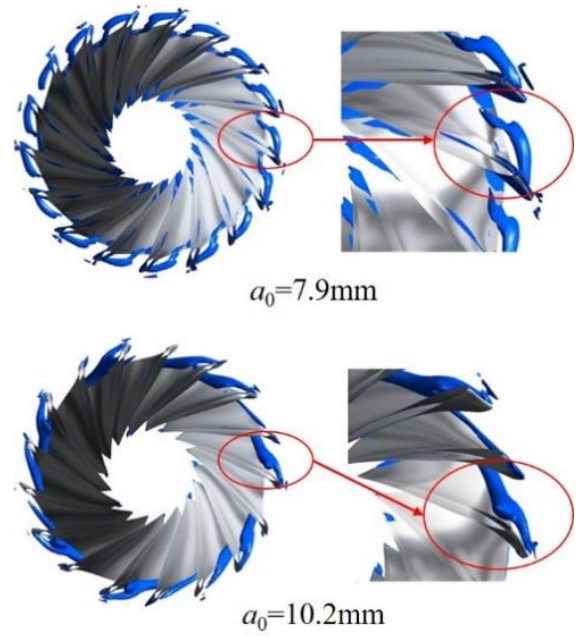

Fig. 4. Vortex structures identified by Q-criterion at different deep part load conditions.

Vortex rope structures were showing by Q-criterion in Fig. 4. The blade vortex rope waving in the blade channel and periodically changing the pressure and velocity distribution. The frequency of the vortex rope waving and the pressure fluctuations agree very well at HSV which is located on the turbine headcover. Thus, the pressure fluctuation in the blade channel was induced by blade vortex rope waving.

\subsection{Formation and evolution of the inter- blade vortex}

The formation and evolution of the inter-blade vortex are strongly connected with velocity distribution in the runner inlet. During deep part load conditions, the flow is subjected to a negative incident angle which is susceptible to cause flow separation and misaligned flow in blade channels.

The streamline near the runner inlet at different operation conditions was showing in Fig. 5 and Fig. 6 . It is indicated that flow separation started from the top of the inlet and extended to the bottom of the runner inlet. At the top of the inlet, the flow separation was rather slightly and only a small backflow occurred in the leading edge of the runner blade. While the flow separation was enhanced and extended to the bottom and downstream of the runner, as the backflow area was enlarged and moved

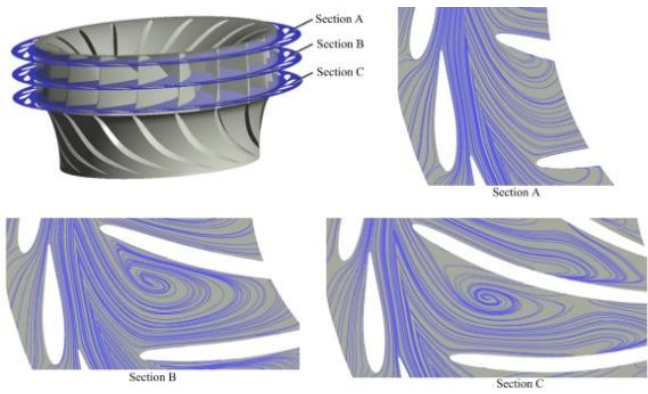

Fig. 5. Streamlines on reference sections at the opening condition of $7.9 \mathrm{~mm}$.

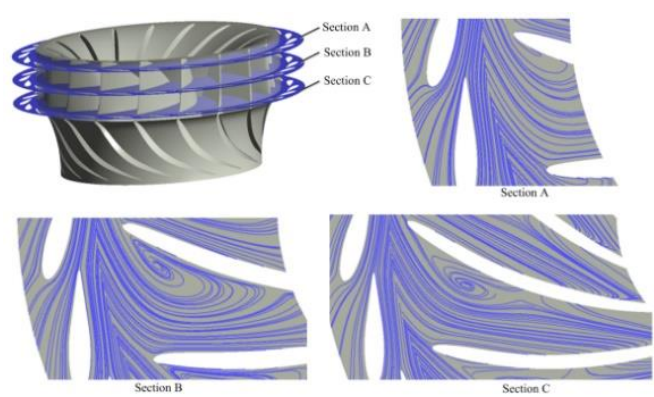

Fig. 6. Streamlines on reference sections at the opening condition of $10.2 \mathrm{~mm}$.

to the trailing edge of the runner blade. As the guide vane opening angle decrease, for example, from 10.2 mm (Fig. 6) to 7.9 (Fig. 5), the flow separation was enhanced and the backflow region was enlarged and moved more to the downstream.

The velocity distribution at different spans is showing in Fig. 7. It showed the same tendency that small flow separation starts from the leading edge of the blade at span 0.9, and backflows occur and enhanced to the whole blade channel at span 0.1.
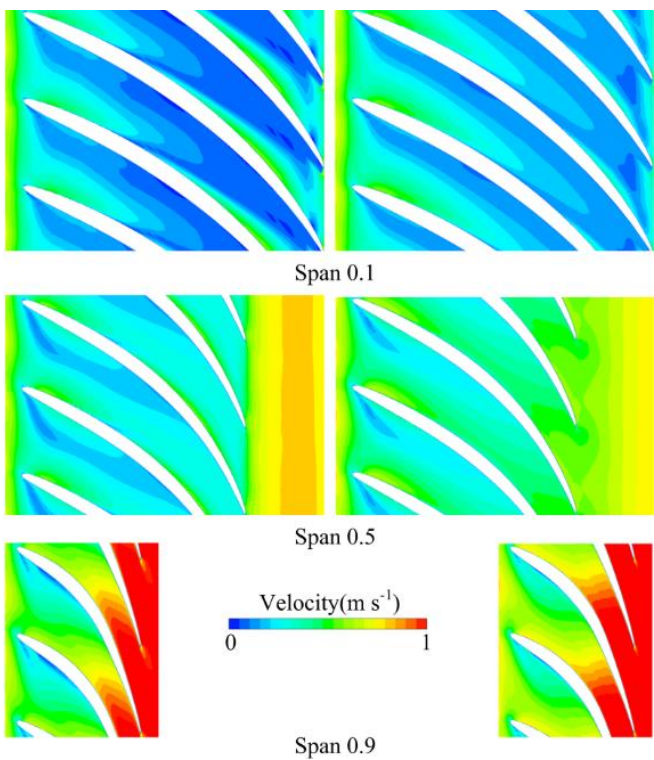

Fig. 7. Velocity distributions at different spans of the turbine at $Q=30 \% Q_{\mathrm{d}}\left(a_{0}=7.9\right)$. 


\subsection{Vortical and energy production analysis}

Intensive vortex flow in the impeller induces significant hydraulic loss as well as pressure oscillations under deep part load conditions, while entropy production theory can be used to determine energy loss in post-processing. Therefore, it is necessary to adopt intuitive methods, vorticity transport equation and entropy production theory to evaluate the performance of hydro turbine on deep part load conditions and capture the interactions between vortex evolution and energy loss.

The vorticity transport equation is.

$$
\begin{aligned}
& \frac{D \vec{\omega}}{D t}= \\
& \underbrace{(\vec{\omega} \cdot \nabla) \vec{V}}_{\mathrm{I}}-\underbrace{\vec{\omega}(\nabla \cdot \vec{V})}_{\mathrm{II}}+\underbrace{\frac{\nabla \rho \times \nabla P}{\rho^{2}}}_{\mathrm{II}}+\underbrace{\left(v+v_{\mathrm{tur}}\right) \nabla^{2} \vec{\omega}}_{\mathrm{IV}}
\end{aligned}
$$

where $\vec{\omega}$ refers to the relative vorticity, $\mathrm{s}^{-1}, \vec{V}$ is time-averaged relative velocity, $\mathrm{m} / \mathrm{s}, \rho$ corresponds to the density, $\mathrm{kg} / \mathrm{m}^{3}, P$ is the pressure, $\mathrm{Pa}$, and $v$ $v_{\text {tur }}$ account for the kinematic viscosity and turbulent viscosity respectively, $\mathrm{Pa} \cdot \mathrm{s}$.

The evolution of vorticity is illustrated by four different terms on the right side: The stretching term (term I) which is induced by velocity gradients, the dilation term (term II) which is induced by volumetric expansion or contraction. The term III and IV are baroclinic torque term and viscous diffusion term, which are ignored based on previous studies.

Intensive vortex flow in the impeller induces significant hydraulic losses. Entropy production theory can be used to determine energy loss in postprocessing. In the process of energy conversion, irreversible energy dissipation and entropy production of the entire system is inevitable from the perspective of the second thermodynamic law. Therefore, the connection between energy dissipation and entropy production can be established directly and entropy production theory is able to measure hydraulic loss in hydro turbine flows. (Li et al. 2016,2017)

The entropy transport equation for incompressible single-phase flow in Cartesian coordinate is shown as follows:

$$
\rho\left(\frac{\partial s}{\partial t}+u \frac{\partial s}{\partial x}+v \frac{\partial s}{\partial y}+w \frac{\partial s}{\partial z}\right)=\operatorname{div}\left(\frac{\vec{q}}{T}\right)+\frac{\Phi}{T}+\frac{\Phi_{\Theta}}{T^{2}}
$$

Following the example of the Reynolds timeaveraged method, the instantaneous variables can be split into the time-averaged part as well as fluctuating part.

$$
s=\bar{s}+s^{\prime}
$$

$$
\begin{aligned}
& u=\bar{u}+u^{\prime} \\
& v=\bar{v}+v^{\prime} \\
& w=\bar{w}+w^{\prime}
\end{aligned}
$$

Combine Eqs. (11) and (12) into Eq. (10) before time-averaged treatment. Then, time-averaged processing is implemented toward Eq. (10) as follows

$$
\begin{aligned}
& \rho\left[\begin{array}{l}
\left(\frac{\partial \bar{s}}{\partial t}+U \frac{\partial \bar{s}}{\partial x}+V \frac{\partial \bar{s}}{\partial y}+W \frac{\partial \bar{s}}{\partial z}\right) \\
+\left(\frac{\partial \overline{u^{\prime} s^{\prime}}}{\partial x}+\frac{\partial \overline{v^{\prime} s^{\prime}}}{\partial y}+\frac{\partial \overline{w^{\prime} s^{\prime}}}{\partial z}\right)
\end{array}\right]= \\
& \operatorname{div}\left(\overline{\left.\frac{\vec{q}}{T}\right)}+\frac{\bar{\phi}}{T}+\frac{\overline{\phi_{\Theta}}}{T^{2}}\right.
\end{aligned}
$$

In the above equation, term I and term II represent the entropy production rate (EPR): term I is induced by viscous dissipation and term II is induced by heat transfer. Given that temperature variation in Francis turbine flow at room temperature is negligible, the EPR by heat transfer (term II) is ignored in this research.

Time-averaged entropy production term I gives two parts, one with time-averaged part and another with the fluctuating part.

$$
\begin{aligned}
& \frac{\bar{\Phi}}{T}=\dot{S}_{\overline{\mathrm{D}}}^{\prime \prime \prime}+\dot{S}_{\mathrm{D}^{\prime}}^{\prime \prime} \\
& \mu_{\mathrm{eff}}=\mu+\mu_{\mathrm{tur}} \\
& \dot{S}_{\overline{\mathrm{D}}}^{\prime \prime \prime}=\frac{\mu_{\mathrm{eff}}}{T}\left[\begin{array}{l}
2\left\{\left(\frac{\partial \bar{u}}{\partial x}\right)^{2}+\left(\frac{\partial \bar{v}}{\partial y}\right)^{2}+\left(\frac{\partial \bar{w}}{\partial z}\right)^{2}\right\} \\
+\left(\frac{\partial \bar{u}}{\partial y}+\frac{\partial \bar{v}}{\partial x}\right)^{2}+\left(\frac{\partial \bar{u}}{\partial z}+\frac{\partial \bar{w}}{\partial x}\right)^{2} \\
+\left(\frac{\partial \bar{v}}{\partial z}+\frac{\partial \bar{w}}{\partial y}\right)^{2}
\end{array}\right] \\
& \dot{S}_{\mathrm{D}^{\prime}}^{\prime \prime \prime}=\frac{\mu_{\mathrm{eff}}}{T}\left[\begin{array}{l}
2\left\{\left(\frac{\partial u^{\prime}}{\partial x}\right)^{2}+\left(\frac{\partial v^{\prime}}{\partial y}\right)^{2}+\left(\frac{\partial w^{\prime}}{\partial z}\right)^{2}\right\} \\
+\left(\frac{\partial u^{\prime}}{\partial y}+\frac{\partial v^{\prime}}{\partial x}\right)^{2}+\left(\frac{\partial u^{\prime}}{\partial z}+\frac{\partial w^{\prime}}{\partial x}\right)^{2} \\
+\left(\frac{\partial v^{\prime}}{\partial z}+\frac{\partial w^{\prime}}{\partial y}\right)^{2}
\end{array}\right]
\end{aligned}
$$

In above equations, $\dot{S}_{\overline{\mathrm{D}}}^{\prime \prime \prime}$ represents the entropy production rate inducted by time-averaged velocity, being referred to as direct dissipation (EPDD). And $\dot{S}_{\mathrm{D}^{\prime}}^{\prime \prime \prime}$ is the entropy production rate induced by fluctuating velocity, often being referred to indirect or turbulent dissipation (EPTD). 
In the RANS method, the fluctuating velocity is not involved in governing equations where only timeaveraged velocity can obtain an iterative solution. So that direct dissipation can be got in CFD postprocessing but turbulent dissipation cannot. Combining with turbulence model $k-\varepsilon$, the right-hand sides of Eq. (9) can be replaced by the product of density $\rho$ and turbulent dissipation rate $\varepsilon$.

$$
\dot{S}_{\mathrm{D}^{\prime}}^{\prime \prime \prime}=\frac{\rho \varepsilon}{T}
$$

For turbulence model $k$ - $\omega$, the right-hand sides of Eq. (9) can be replaced by the following equation.

$$
\dot{S}_{\mathrm{D}^{\prime}}^{\prime \prime \prime}=\beta \frac{\rho \omega k}{T} \quad(\beta=0.09)
$$

Note that a fairly fine mesh is required near-wall because entropy production has peak values in the vicinity of the wall when $y+<50$. But RANS method cannot capture the steep gradients near the wall with acceptable grid elements and there is great inconsistency with DNS results in $\mathrm{y}+<50$ regions. Therefore, the wall function used to calculate entropy production inside the first grid near the wall was proposed by Duan et al. (2016) to avoid the unacceptable error by the RANS method.

$$
S_{\mathrm{W}}=\int_{A} \dot{S}_{\mathrm{W}}^{\prime \prime} d A=\int_{A} \frac{\vec{\tau} \cdot \vec{v}_{\mathrm{w}}}{T} d A
$$

Hence, the total entropy production rate (TEPR) can be expressed as:

$$
\dot{S}_{\mathrm{Total}}^{\prime \prime \prime}=\dot{S}_{\overline{\mathrm{D}}}^{\prime \prime \prime}+\dot{S}_{\mathrm{D}^{\prime}}^{\prime \prime \prime}+\dot{S}_{\mathrm{W}}^{\prime \prime \prime}
$$

And the corresponding energy loss is as follows:

$$
\begin{array}{ll}
S_{\overline{\mathrm{D}}}=\int_{V} \dot{S}_{\overline{\mathrm{D}}}^{\prime \prime \prime} d V \quad S_{\mathrm{D}^{\prime}}=\int_{V} \dot{S}_{\mathrm{D}}^{\prime \prime \prime} d V & S_{\mathrm{W}}=\int_{A} \dot{S}_{\mathrm{W}}^{\prime \prime \prime} d A \\
P_{\bar{D}}=T \cdot S_{\bar{D}} \quad P_{D^{\prime}}=T \cdot S_{D^{\prime}} \quad P_{W}=T \cdot S_{W} \\
P_{\text {Total }}=P_{\bar{D}}+P_{D^{\prime}}+P_{W} & \\
S_{\text {Total }}=S_{\bar{D}}+S_{D^{\prime}}+S_{W} &
\end{array}
$$

Based on the theory above, the entropy production can be obtained in CFD post-processing by volume integral of the entire domain and surface integral of the wall. Facts prove that the entropy production theory has the advantage of energy loss calculation quantitatively and observes where and how energy dissipation is distributed intuitively.

Thus, the interaction between vortex evolution and local entropy production can be further investigated by analyzing the effects of different terms which is showing in Fig. 8 to Fig. 9. It is indicated in Fig. 8 that the vorticity formed at the leading edge (L.A.) of the suction surface and the trailing edge (T.A.) of the pressure surface in the blade channels. The vorticity in the leading edge detached from the suction surface, it increased from span 0.2 to span 0.9 and finally almost run through the whole blade channel at span 0.9. While vorticity in the trailing edge attached to the pressure surface and decreased from span 0.2 to span 0.9 . It proved that at deep part load conditions, a large attach angle induced the flow separation and formed detached vortex rope in the blade channel.

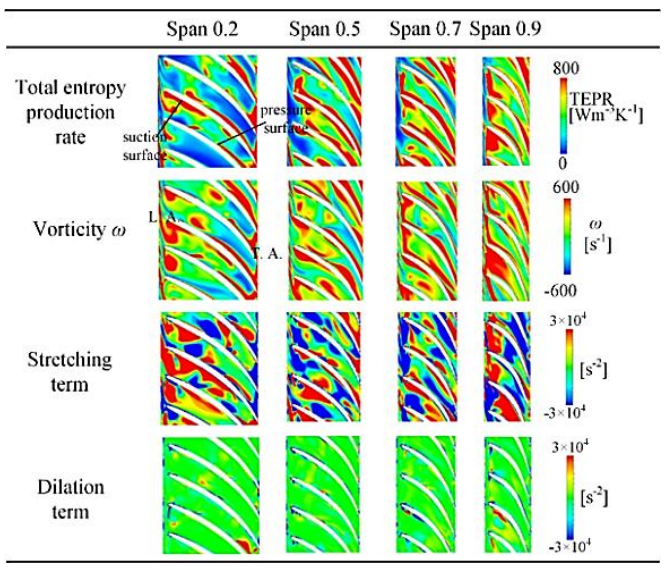

Fig. 8. Distributions of local entropy production rate, vorticity, stretching and dilation term at different spans at $Q=30 \% Q_{\mathrm{d}}$.

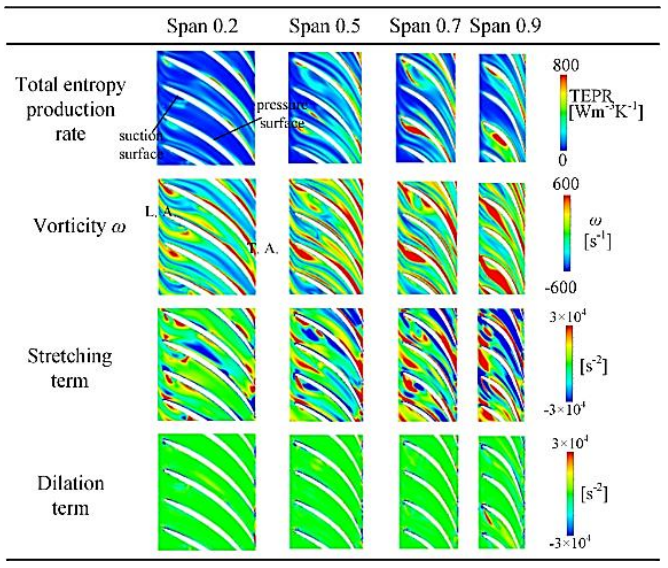

Fig. 9. Distributions of local entropy production rate, vorticity, stretching and dilation term at different spans at $Q=40 \% Q_{\mathrm{d}}$.

With the blade vortex developed in the blade channel, Fig. 8 also shows the contribution of each term. Since cavitation does not occur and the viscous diffusion term is much smaller than other terms, these two terms were ignored. It is indicated that the stretching term provides the most vorticity increments of the detached vorticity at the leading edge since the stretching term distribution is consistent with the vorticity distribution. Also, the stretching term provides some decrement at the trailing edge of the pressure surface. The dilation term mainly distributed at the trailing edge of the pressure surface and act as an inhibiting part, which only provides decrement of the vorticity evolution.

Since vortex evolution is closely connected with energy loss, the total entropy production distribution is consisting with the distribution of vorticity. The 
total entropy mainly distributed at the suction surface of the blade leading edge where the stretching term providing large vorticity. As the vorticity increased from span 0.2 to span 0.9 , entropy production increased a lot. This indicated that the vortex stretching in the blade channels, causing large energy loss at deep part load conditions. While with the discharge rate $Q / Q_{\mathrm{d}}$ increased from $30 \%$ to $40 \%$, flow in the blade channel became more uniform, as showing in Fig. 9. The flow separation is of rare occurrence at the leading edge of the blade. Little entropy production distributed in the leading edge indicated little energy losses in this area. While at the trailing edge of the blade, especially from span 0.7 to 0.9 , the stretching term providing large vorticity, and the energy loss increased. This illustrated that as the discharge rate increased from $30 \%$ to $40 \%$, the operating condition transforming from deep part load condition to part load condition. Flow separation mainly occurred at the runner outlet and then causing vortex rope in the draft tube.

The entropy production for various discharge conditions are shown in Fig. 10. It indicates that total entropy production decreases with discharge rate $Q / Q_{\mathrm{d}}$ increasing. In addition, EPDD and EPTD keep the same proportion for different discharge conditions. At deep part load condition $\left(Q / Q_{\mathrm{d}}\right.$ $=30 \%$ ), EPDD and EPTD provide the most entropy (more than $80 \%$ ), while at part load condition the proportion of these two-part decrease to $50 \%$. This means that at part load condition, energy loss caused by EPWS increased.

The total entropy production at different parts of the whole passage is showing in Fig. 11. It is indicated that the entropy production in the runner and draft tube provides $90 \%$ of the total entropy production of the whole passage. Although the draft tube provides the most entropy production at each condition, the entropy production in runner at deep part condition is obviously larger than that at part load conditions. This means the energy loss in runner at deep part load condition needs special attention.

\section{Conclusion}

In this research, the vortex evolution and energy production were investigated based on the vortex transport equation and entropy production theory. The modified PANS method was adopted in the study and the characteristics of energy production was analyzed subsequently by embedding entropy expressions into software ANSYS CFX code. The entropy production theory can be used to the calculation of efficiency and the analysis of irreversible hydraulic loss in Francis turbine. The conclusions can be drawn as:

(1) The modified PANS method shows significant advantages in hydro turbine's simulation than traditional RANS method. It can predict the flow rate and efficiency more accurately.

(2) At deep part load condition, the vorticity formed at the leading edge of the suction surface and the trailing edge of the pressure surface in blade

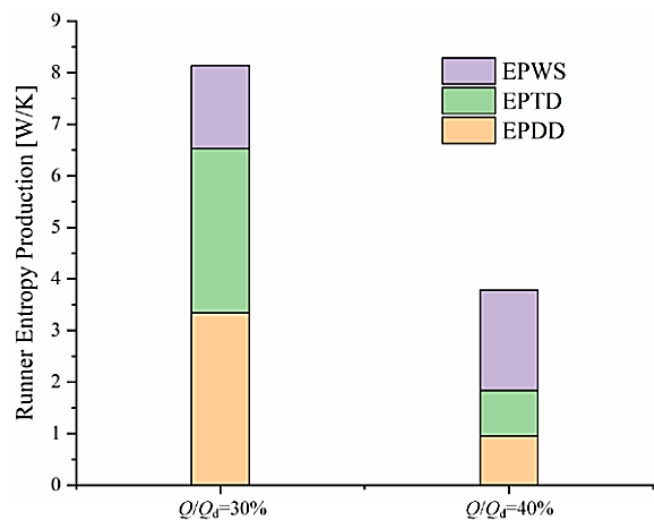

Fig. 10. Total and different entropy production terms in runner versus discharge.

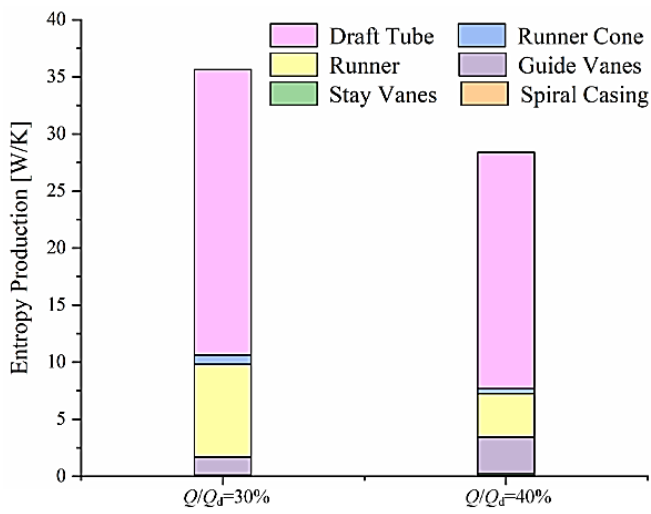

Fig. 11. Total entropy production at different part of the whole passage.

channels. The vorticity in the leading edge detached from the suction surface, it increased from span 0.2 to span 0.9 and finally almost run through the whole blade channel at span 0.9. While vorticity in the trailing edge attached to the pressure surface and decreased from span 0.2 to span 0.9. It proved that at deep part load conditions, large attach angle induced the flow separation and formed detached vortex rope in the blade channel.

(3) The stretching term provides the most vorticity increments of the detached vorticity at the leading edge and some decrement at the trailing edge of the pressure surface. While the dilation term mainly distributed at the trailing edge of the pressure surface and act as an inhibiting part, which only provides decrement of the vorticity evolution.

(4) The total entropy production distribution is consisting with the distribution of vorticity. At deep part load condition (Q/Qd $=30 \%$ ), EPDD and EPTD provide the most entropy (more than $80 \%$ ), while at part load condition the proportion of these two-part decrease to $50 \%$. 


\section{ACKNOWLEDGEMENTS}

This research was funded by the National Natural Science Foundation of China (Project No. 51806058), the Fundamental Research Funds for the Central Universities (Project No. B200202170) and Advanced Space Propulsion Laboratory of BICE and Beijing Engineering Research Center of Efficient and Green Aerospace Propulsion Technology (Project No. LabASP-2019-09).

\section{REFERENCES}

Amet, E., T. Matîre, C. Pellone and J. L. Achard, (2009). 2D numerical simulations of blade vortex interaction in a darrieus turbine, Journal of Fluids Engineering-Transactions of the ASME 131, 111103.

Chen, J., G. Li and S. Liu (2007). The occurrence and the influence of the inter-blade vortex on the hydraulic turbine stability, Large Electric Machine and Hydraulic Turbine 119, 221-234.

Cheng, H., L. Zhou, Q. Liang, Z. Guan, D. Liu, Z. Wang and W. Kang (2020). The investigation of runner blade channel vortices in two different Francis turbine models, Renewable Energy 156, 201-212.

Doussot, F., G. Balarac, J. Brammer (2019). Laurant and O. Métais, RANS and LES Simulations at Partial Load in Francis Turbines: ThreeDimensional Topology and Dynamic Behaviour of Inter Blade Vortices, International Journal of Fluid Machinery and Systems 13, 2020.

Duan, L., X. Wu, Z. Ji, Z. Xiong and J. Zhuang (2016). The flow pattern and entropy generation in an axial inlet cyclone with reflux cone and gaps in the vortex finder. Powder Technology 303,192-202.

Escaler, X., E. Egusquiza, M. Farhat, F. Avellan and M. Coussirat (2006). Detection of cavitation in hydraulic turbines, Mechanical Systems and Signal Processing 20, 983-1007.

Herwig, H. and K. Fabian (2006) Direct and indirect methods of calculating entropy generation rates in turbulent convective heat transfer problems. Heat and Mass Transfer 43(3),207-215.

Huang, R., X. Luo, B. Ji and Q. Ji (2017). Turbulent flows over a backward facing step simulated using a modified Partially-Averaged NavierStokes model, Journal of Fluids EngineeringTransactions of the ASME 139, 044501.

Jing, Z. and A. Ducoin (2020). Direct numerical simulation and stability analysis of the transitional boundary layer on a marine propeller blade, Physics of Fluids. 32 (12), 124102.

Kock, F. and H. Herwig (2004). Local entropy production in turbulent shear flows: a highReynolds number model with wall functions.
International Journal of Heat and Mass Transfer 47(10-11), 2205-2215.

Kock, F. and H. Herwig (2005). Entropy production calculation for turbulent shear flows and their implementation in CFD codes. International Journal of Heat \& Fluid Flow 26(4),6726-80.

Kumar, P. and R. P. Saini (2010). Study of cavitation in hydro turbines-A review. Renewable \& Sustainable Energy Reviews 14, 374-383.

Kurosawa, S., S. M. Lim and Y. Enomoto (2010). Virtual model test for a Francis turbine, 25th IAHR Symposium on Hydraulic Machinery and Systems, Earth \& Environmental Science, Timisoara, 793-798.

Liu, D., X. Liu and Y. Zhao (2017) Experimental Investigation of Inter-Blade Vortices in a Model Francis Turbine, Chinese Journal of Mechanical Engineering 30, 854-861.

Li, D., R. Gong, H. Wang, G. Xiang, X. Wei and D. Qin (2016). Entropy Production Analysis for Hump Characteristics of a Pump Turbine Model, Chinese Journal of Mechanical Engineering 29,803-812.

Li, D., H. Wang, Y. Qin, L. Han, X. Wei and D. Qin (2017). Entropy production analysis of hysteresis characteristic of a pump-turbine model, Energy Conversion and Management 149, 175-191.

Luo, X., B. Ji and Y. Tsujimoto (2016). A review of cavitation in hydraulic machinery [J]. Journal of Hydrodynamics28(3), 335-358.

Méndez, M., S. Shadloo, A. Hadjadj and A. Ducoin (2018). Boundary Layer Transition Over a Concave Plate Caused by Centrifugal Instabilities, Computers \& Fluids 171, 135-153.

Roth, S., V. Hasmatuchi and F. Avellan (2010). Advanced instrumentation for measuring fluidstructure coupling phenomena in the guide vanes cascade of a pump-turbine scale model, Proceedings of the ASME 20103rd joint USEuropean fluids engineering summer meeting, Montreal, Canada.

Wack, J. and S. Riedelbauch (2015). Numerical simulations of the cavitation phenomena in a Francis turbine at deep part load conditions, Journal of Physics: Conference Series 656, 012074 .

Wang, W., L. Zhang and Y. Yan (2007). Large-eddy simulation of turbulent flow considering inflow wakes in a Francis turbine blade passage, Journal of Hydrodynamics 19, 201-209.

Xiao, Y., Z. Wang and Z. Yan (2011). Experimental and numerical analysis of blade channel vortices in a Francis turbine runner, Engineeting Computation 28, 154-171.

Yamamoto, K. A. Müller, A. Favrel and F. Avellan (2019). Physical mechanism of inter-blade vortex development at deep part load operation of a Francis turbine, Journal of Fluids 
A. Yu et al. / JAFM, Vol. 14, No. 6, pp. 1669-1678, 2021.

Engineering-Transactions of the ASME 141, 111113.

Yamamoto, K., A. Müller, A. Favrel and F. Avellan (2017). Experimental evidence of inter-blade cavitation vortex development in Francis turbines at deep part load condition, Experiments in Fluids 58, 142.

Yamamoto, K., A. Mülle, A. Favrel and F. Avellan (2016). Numerical and experimental evidence of the inter-blade cavitation vortex development at deep part load operation of a Francis turbine, IOP Conference Series: Earth and Environmental Science 49, 082005.
Yamamoto, K., A. Müller and A. Favrel (2015) Landry, Guide vanes embedded visualization technique for investigating Francis runner interblade vortices at deep part load operation. 6th IAHR International Meeting of the Workgroup on Cavitation and Dynamic Problems in Hydraulic Machinery and Systems.

Zuo, Z., S. Liu, D. Liu, D. Qin and Y. Wu (2015). Numerical analyses of pressure fluctuations induced by interblade vortices in a model Francis turbine, Journal of Hydrodynamics 27, 513-521. 